\title{
Phytotherapeutical Alternatives for the Treatment of Benign Prostatic Hyperplasia in Obesity
}

\author{
Juventino III Colado-Velázquez*, Patrick Mailloux-Salinas, J. M. de Lourdes Medina-Contreras, \\ Fabian Meza-Cuenca and Guadalupe Bravo
}

\author{
CINVESTAV-IPN, Czda.delos Tenorios 235, Col. Granjas Coapa, 14330, Mexico
}

\begin{abstract}
Benign prostatic hyperplasia is a very common urinary disorder affecting middle-aged men, giving place to lower urinary tract symptoms, which are detrimental to the quality of life. Obesity increases the risk and severity of its symptoms requiring earlier medical interventions for its treatment. Current pharmacotherapy has serious adverse effects that can lead to discontinuation of the treatment. Phytotherapy is an alternative being used in European countries for several years; however, the evidence for its efficacy is contradictory and remains to be clearly defined. It is of transcendental importance to homogenize quality of plant extracts, as well as to test them in specific age groups to obtain evidence whether plant extracts alone or in combination have the potential to serve as the only therapy or as adjuncts with more traditional treatments for BPH. This review also assesses the fact that no clinical trials have been performed in obese patients, despite the direct link between obesity and prostate disease.
\end{abstract}

Keywords: Obesity, benign prostate hyperplasia, phytotherapy.

\section{INTRODUCTION}

Obesity is a chronic and multifactorial disease manifested by the excessive accumulation of body fat produced by a positive energy balance, due to an excess of caloric and intake fat exceeding the energy released. This brings as a consequence severe health complications which caused it to stop being an aesthetic problem and to become a main public health concern. The World Health Organization (WHO) categorizes obesity as a condition defined by a body mass index (BMI) larger than 30 [1]. Phenotypically there are four types of excess body weight: Peripheral, android, gynoid and central. Obesity has a multifactorial etiology; these factors include genetic metabolic traits, endocrine regulation of appetite, environmental factors, sociocultural and psychological characteristics as well, all of which can derive in an energetic imbalance related to food intake. When energy intake surpasses expenditure, excess calories accumulate in adipose tissue, and if this balance is maintained for a significant amount of time the end result is obesity $[2,3]$.

Several molecules acting through a feedback system regulate food consumption such as leptin [4], ghrelin [5, 6], neuropeptide Y [6] and melanocortin [7]; an imbalance in the secretion of these substances, as well as the development of resistance can alter food intake by modifying satiety responses which in turn can cause overfeeding and then fat accumulation as a direct consequence [1]. Another mechanism for obesity development is a decrease in metabolic

*Address correspondence to this author at the CINVESTAV-IPN, Czda.delos Tenorios 235, Col. Granjas Coapa, 14330, Maxico;

Tel: +52 55 54832858; Fax: +525550612863; E-mail: gbravof@yahoo.com response due to environmental influences, pharmacological side-effects of medication and hormonal imbalances which can also mediate the apparition of concomitant diseases $[8$, 9].

In 2008, the WHO reported that obesity along with overweight represented the fifth risk factor for premature death in the world, it was estimated that one out of ten adults in the world population presented obesity [10]. Obesity is the main cause for increase of chronic non-transmissible disease such as cardiovascular alterations, type II diabetes, gall bladder disease, cancer and lower urinary tract disorders [1].

\section{BENIGN PROSTATIC HYPERPLASIA}

Benign prostatic hyperplasia (BPH) is a common disease which has been associated to age and originates the development of various symptoms. BPH often leads to complications such as obstructive urinary symptoms, infections, known as Lower Urinary Tract Symptoms (LUTS); and if left untreated can cause the development of renal dysfunction, most patients with BPH are only treated for symptomatic improvement [11-13]. There is a considerable number of hormones and growth factors regulating prostate growth, among them we can mention endocrine factors such as androgens (testosterone, dihydrotestosterone) [14, 15], prolactin and insulin; neuroendocrine signals (5-hydroxytriptamine, noradrenalin) [16]; growth factors such as fibroblast growth factor (FGF-2), epidermal growth factor (EGF) [17]. It has been described that estrogen along with androgen stimulate prostatic stroma, upregulating androgen receptors and increasing production of the enzyme $5 \alpha$-reductase which in turn increases dihydrotestosterone (DHT) in the prostate 
Table 1. Most common pharmacological treatments for BPH and adverse effects.

\begin{tabular}{|c|c|}
\hline $\begin{array}{l}\text { 5 } \alpha \text {-reductase } \\
\text { Inhibitors } \\
\text { (Finasteride). }\end{array}$ & $\begin{array}{l}\text { Impotence, testicular pain, gynecomastia, } \\
\text { weight gain, decreased libido, ejaculation } \\
\text { alterations, nausea and hot flashes }\end{array}$ \\
\hline $\begin{array}{l}\alpha \text {-adrenergic } \\
\text { blockers } \\
\text { (Tamsulosin and } \\
\text { Prasozin). }\end{array}$ & $\begin{array}{l}\text { Priaprism, ejaculation alterations, dizziness, } \\
\text { rash, edema, hypotension, headache }\end{array}$ \\
\hline $\begin{array}{l}\mathrm{Ca}^{2+} \text { channel } \\
\text { blockers } \\
\text { (Nifedipine and } \\
\text { Amlodipine). }\end{array}$ & $\begin{array}{l}\text { Hypotension, nausea, dizziness, fatigue, } \\
\text { arrythmias. }\end{array}$ \\
\hline
\end{tabular}

$[18,19]$. It has been demonstrated that insulin has an influence in glandular growth and has a permissive effect on the androgenic action in prostatic tissue $[14,20,21]$. A nonsteroidal factor regulating prostate growth and differentiation is prolactin, which exerts its effect in an androgenindependent fashion by modulating other growth factors. In men prolactin levels are increased with age and have been related to BPH development [22]. All these factors in combination promote prostate growth and proliferation.

\section{OBESITY AND BPH}

Body fat accumulation and obesity have been related with alterations in the size and weight of some organs due to endocrine effects caused by adipose tissue. These effects include modifications in the synthesis and bioavailability of sex hormones; growth factor and cytokine release [23] a direct relationship has been reported between obesity and prostate disorder incidence such as BPH and prostate cancer as well as a significant increase in the risk for LUTS [24]. Excess in adipose tissue also increases sympathetic activity, this has been associated with an increase prostate tissue contractility, as well as an increase in the release of androgens which in turn promote prostate growth [17].

In obesity there is development of insulin resistance, which leads to glucose intolerance and other alterations which can lead to the development of metabolic syndrome; this leads to altered reactive oxygen species (ROS) production and a low-grade inflammation status which subsequently alter the production of growth factors in prostatic tissue increasing the size of the gland in a non-androgen dependent mechanism $[25,26]$. Inflammation plays an important role, since ROS themselves can cause tissue damage, increasing nitric oxide production by activation of the inducible nitric oxide synthase (iNOS). This nitric oxide excess can react with ROS and form peroxynitrites causing tissue damage and worsening the inflammatory condition in the prostate [27-29]. Obesity increases $10 \%$ the relative risk for $\mathrm{BPH}$ and cancer, there is an association between age and development of prostatic pathologies. An obese individual will present abnormal prostate growth in average of five years earlier than a lean individual [30,31].

\section{Current Therapies for the Treatment of BPH}

The main objective of the treatment for patients with $\mathrm{BPH} / \mathrm{LUTS}$ is to improve their quality of life; the most common pharmacological treatments (Table 1) have significant adverse effects affecting the quality of life of the patients which in turn causes discontinuation of therapy with subsequent worsening of the symptoms.

Among the most prescribed treatments we find $5 \alpha-$ reductase inhibitors such as finasteride which competitively inhibits the enzyme, decreasing the conversion of testosterone to dihydrotestosterone which in turn decreases prostatic volume and ameliorates obstructive symptoms, another examples of these agents are episteride and duasteride; the main adverse effects for these drugs are the development of gynecomastia, erectile dysfunction and decrease in libido; all of which are reversible upon discontinuation of the treatment $[18,19,32]$.

Among the alternative therapies that have been studied; phytotherapy might be appropriate for many men with $\mathrm{BPH}$ because of the lower incidence of side effects that are detrimental to the quality of life of the patients.

\section{Phytotherapeutic Agents Used on BPH}

The composition of plant extracts used to treat $\mathrm{BPH}$ is very complex. Among the chemical compounds they contain we can find phytosterols, alkaloids, fatty acids and phytoestrogens (Table 2). In plant extracts, often it is unknown which of these compounds is the "active" component and it has been hypothesized that the combination of all components is what gives the actual effect [33-35]. Standardization is a significant problem regarding plant extracts; the vast majority are unique due to the fact that variations in the concentrations of active compounds vary among plants due to several factors during the growth and harvest; the extraction processes are usually different and use various solvents and procedures which can in turn give different concentrations of the actives $[34,36]$. For these reasons, phytotherapeutic preparations from the same plant produced by different companies will differ in their composition and the concentration of the "active compound" in each preparation will also be different [37].

Previous studies regarding phytotherapeutic agents have not been properly designed, most studies included very small numbers of patients, the treatment was not performed in an adequate amount of time and the analysis of the results did not follow strict standards which led to biased conclusions. In recent years there have been better studies being performed, some of which have been funded by companies trying to benefit from the results leading to uncertainties regarding the objectivity of their conclusions.

Phytotherapy has not been given the proper attention in the American continent; they have been generally considered as nutritional supplements and have not been subject to serious studies regarding their efficacy as well as their therapeutic potential; there is little financial incentive for non-US companies to introduce these products in America because of the lack of patent protection for phytotherapeutical preparations. A lack of standardization of the extracts is another problem, which probably has led to inconsistencies in the results of the different clinical trials $[35,38]$. 
Table 2. Active components in natural extracts for the treatment of BPH.

Phytosterols $\quad \beta$-sitosterol, $\Delta$-5-sterol, $\Delta$-7-sterol, campesterol, stigmasterol

Phytoestrogens Genistein, flavonoids, coumestrol

\begin{tabular}{ll}
\hline Terpenoids & $\begin{array}{l}\text { Lectins, polysaccharides, aliphatic } \\
\text { alcohols, fatty acids, free esterified plant } \\
\text { oils }\end{array}$ \\
\hline Carotenoids & $\begin{array}{l}\text { Lycopene, b-carotene, phytoene, } \\
\text { phytofluene }\end{array}$
\end{tabular}

\section{Serenoa Repens (Saw Palmetto)}

In the United states there are many companies producing and selling saw palmetto in various forms; some selling the dry powder of the berries while others selling lipidosterolic extracts with different production methods; this leads to a very inconsistent array of products available, some of which can have little to no effect in ameliorating LUTS. In Europe, most of the serious studies of saw palmetto have been performed in a patented product by Pierre-Fabré Médicaments called Permixon ${ }^{\circledR}$. The results from these studies might not be significant for consumers in America due to the great variability in the products available for consumers. This situation is similar in Latin America, in recent years a huge number of so-called "miracle products" have been marketed, offering cures for a number of diseases by using herbal agents but not offering any evidence or serious studies to back their claims.

Several clinical trials regarding the efficacy of saw palmetto have been published in the past. The vast majority have been uncontrolled studies, which have not provided enough evidence to determine the efficacy of the extracts tested. For example, an open-label study performed on 50 patients treated with Serenoa repens for 6 months, showed an improvement of symptoms but found no significant effect in other parameters such as flow rate and bladder pressure [39] showing a significant placebo-effect in symptom perception. In contrast, another study of 75 patients treated with Permixon $^{\circledR}$ (lipidosterolic Serenoa repens extract) found a significant improvement in urodynamic parameters in comparison to placebo [40].

Most of these published studies have important issues; none of them assessed the criteria developed by the International Consultation on $\mathrm{BPH}$ for evaluating treatment outcome in men with BPH/LUTS. The main limitations of these studies are the limited amount of patients, sub-chronic treatment (1 to 3 months), and the lack of standardized evaluation methods, which makes very difficult to compare the observed effects in one study with another. For example, in 2 meta-analyses evaluating the efficacy of saw palmetto, nocturia was the only symptom in common. In one metaanalysis. of 18 trials involving 2939 patients using various Serenoa repens preparations, the mean weighted difference between patients treated in comparison to placebo for nocturia was -0.76 times per evening in 10 of the studies reviewed [38]. Another meta-analysis of 13 trials involving 2859 patients using only Permixon ${ }^{\circledR}$ brand of Serenoa repens, the reduction in nocturia was not significant [41]. The variations in the conditions of these trials, makes a metaanalysis inconclusive and subject to bias.

Other markers, such as peak urinary flow rates, were also evaluated in some of the studies reviewed in the metaanalyses. Wilt et al. found that $S$. repens extracts improved peak urinary flow in comparison to placebo by a mean weighted difference of $1.93 \mathrm{~mL} / \mathrm{s}(0.72$ to 3.14$)$ [38]. In comparison, Boyle et al. showed that Permixon ${ }^{\circledR}$ was associated with a mean reduction in the International Prostate Symptom Score (IPSS) of $4.78(0.41)$. Placebo exerted a mean effect on increasing peak urinary flow rate by $1.20(0.49) \mathrm{mL} / \mathrm{s}$ while the effect of Permixon ${ }^{\circledR}$ was a mild increase of $1.02(0.50) \mathrm{mL} / \mathrm{s}$. Placebo was associated with a reduction in the mean number of nocturnal voids of $0.63(0.14)$; whereas the effect of Permixon ${ }^{\circledR}$ was of $0.38(0.07)$. The studies considered in the meta-analyses showed heterogeneity regarding nocturia; one of the studies comprising over 2 years with 396 patients showed no difference between placebo and Permixon ${ }^{\circledR}$; this study had a large bias effect on the results [41].

A more recent trial, the Complementary and Alternative Medicines for Urological Symptoms (CAMUS) performed in 2011, comprised 3300-participant, treated with Serenoa repens, Pygeum africanum, an alpha adrenergic blocking drug and placebo [42]. Results from this trial show that after 72 weeks of treatment, mean American Urological Association Symptom Index (AUASI) scores decreased significantly with both saw palmetto and placebo; showing a significant placebo effect. The group mean difference in AUASI score change after 72 weeks between the saw palmetto extract and placebo groups was 0.79 points favoring placebo. This trial found that this preparation of saw palmetto was not significantly different from placebo.

This contrasts with more recent trials showing a positive effect of saw palmetto in combination with selenium and lycopene, a sample of 102 patients were randomized into two groups: The first one receiving the combination or saw palmetto for 8 weeks. The evaluation parameters for this study were the National Institutes of Health-Chronic Prostatitis Symptom Index (NIH-CPSI), IPSS, maximum peak flow rate (MPFR), and prostatic specific antigen measurements at weeks 4,8 during treatment and 8 weeks after the end of treatment. The study found that a significant decrease in mean NIH-CPSI among both groups; a significant decrease in the total score from 27.45 to 13.27 in the combination group $(-51.64 \%)$ and from 27.76 to 20.62 for $S$. repens alone $(-26.06 \%)$. There was a significant improvement in IPSS scores in both groups, but was more pronounced in the combination group. PSA and white blood cell count decreased significantly in the combination-treated group, MPFR showed better improvement in this group as well [43]. Another trial of the same combination was performed in 168 patients with BPH/LUTS. The patients were subdivided in two groups; the first group consisted of 108 subjects, with 
histological diagnosis of prostatic chronic inflammation (PCI) associated with $\mathrm{BPH}$, randomly assigned to $1: 1$ ratio to treatment with the combination for 6 months or to control group; the second group consisted of 60 subjects with histological diagnosis of $\mathrm{BPH}$, randomly assigned to daily treatment with the combination and $\alpha$-blockers for 3 months. After treatment, biopsies were taken and specimens were evaluated for changes in inflammation parameters and cellular density for T-cells, B-cells and macrophages. The trial found statistical significant reductions of mean values of CD20, CD3, CD68 and mean PSA value in saw palmetto treated groups compared to control, the study showed a statistically significant reduction in the density of CD20, CD3, CD68, CD8 in group II compared to control [44].

Regardless of the results in these recent studies, there is still controversy regarding the efficacy of saw palmetto in the treatment of BPH/LUTS. Larger multi-centric studies might hold the key to elucidating the benefits of phytotherapy for the treatment of this disease. No current studies have taken in account body mass index nor the incidence of metabolic syndrome, for this reason it is important to verify the benefits of saw palmetto in obese patients.

\section{Lycopersicum Esculentum (Tomato)}

L. esculentum is a herbaceus plant native to Latin America commonly used as food. Tomatoes are rich in lycopene, which is a long chain poly-unsaturated carotenoid responsible for the red color; lycopene contains eleven conjugated double bonds. Because of this configuration, lycopene has a strong antioxidant activity by interacting and inactivating reactive oxygen species [45-47]; its effects on prostatic tissue have been described mostly in preclinical studies on prostatic cancer experimental models. It has been found that lycopene can inhibit cell proliferation induced by growth factors $[48,49]$ and downregulation of type $15 \alpha$-reductase [50]; it has shown anti-inflammatory activity by modulating cyclooxygenase activity [48]. In vivo experiments have shown contradictory results regarding effects of lycopene or tomato extracts regarding reduction of plasma testosterone levels; mostly due to treatment duration, lycopene dosage or differences in experimental models [51]. Some studies have shown that tomato extract is more effective than lycopene alone in inhibiting cancer cell proliferation [51, 52]. The effective dose of lycopene has been disputed; some studies report that $7 \mathrm{mg}$ /day are enough to show beneficial effects, however, other studies report that a minimum of $35 \mathrm{mg} /$ day are needed to show beneficial effects in prostatic tissue [53, 54].

Our research group has recently submitted a patent application in Mexico (MX/a/2014/015563) for a lipidic tomato extract formulation [55]; our results show that our extract has significant activity reducing TNF- $\alpha$, IL-1 $\beta$ and IL-6 in $\mathrm{BPH}$, as well as increasing antioxidant activity (superoxide dismutase, catalase and total glutathione) which in turn decreased malondialdehyde and total nitrites in the prostates of obese rats; the treatment with the extract also significantly reduced prostate weight and improved smooth muscle contractility to norepinephrine.

There are very few clinical studies involving the use of lycopene for the treatment of prostatic disease. A significant decrease in prostatic specific antigen, oxidative stress markers and an increase in cell apoptosis has been reported in patients with adenocarcinoma or BPH at a dose of $15 \mathrm{mg}$ /day [56-58]. Lycopene is often given in association with Serenoa repens $[33,44]$ to improve the clinical effect. More controlled and randomized clinical studies must be performed to properly assess the usefulness of lycopene or tomato extracts in Benign Prostatic Hyperplasia.

Lycopene has low toxicity and the FDA regards it as substance generally recognized as safe. Its adverse effects are mild and reversible upon discontinuation of the treatment; they include gastrointestinal irritation, flatulence, itchy skin, etc [57]. High doses of lycopene can cause accumulation in tissues giving place to yellow-orange skin color and hepatic symptoms [53, 59].

More studies are required to determine the specific mechanism of action and compounds involved in the beneficial effects of L. esculentum in prostate health.

\section{Pygeum africanum (African Plum)}

Pygeum africanum $\left(\right.$ Tadenan $\left.^{\circledR}\right)$, has been postulated to have additional beneficial effects on BPH/LUTS [60]. Levin et al. using a rabbit model with partial bladder outlet obstruction, demonstrated that pretreatment with $P$. africanum exerted changes in bladder mass, decrease in compliance, and alterations in contractile response to adrenergic agonists and electrostimulation [61].

A meta-analysis of trials with Pygeum africanum comprised 2262 patients treated with this extract; 1810 in openlabel studies and 452 in comparative trials. Between 1972 and 1990, 12 double-blind, placebo-controlled studies were completed between 1972 and 1990. However, as limitations, only one study had more than 100 patients and none had duration longer than 12 weeks or used standardized symptom scores for evaluating treatment outcome. Because of this, none of those trials involved in the meta-analysis meet the guidelines recommended by the International Consultation Conferences on BPH; for this reason, the data obtained on the efficacy of Pygeum africanum is deemed to be not conclusive $[62,63]$.

\section{Urtica Dioica}

Urtica extracts are often used in Germany for the treatment of BPH/LUTS, it has been part of traditional medicine in that country. The extracts used are basically tinctures and aqueous extractions. The preparations vary depending on the company, in the same way, as saw palmetto extracts are very different; there is an enormous lack of standardization regarding the actives present in the extracts, as well as the methods employed in the extraction process. The proposed mechanisms of action include the inhibition of growth factors (FGFb, VEGF) and anti-androgenic effects by the inhibition of the conversion of testosterone to DHT.

Few clinical trials have tried to evaluate efficacy of stinging nettle. Most of them involve other phytotherapeutic agents in combination ( $P$. africanum and $S$. repens), making it difficult to evaluate the efficacy of Urtica alone. One of these studies compared two different doses of a combined extract of Urtica and Pygeum [64] while another trial com- 
pared a combination of S. repens and Urtica (Prostagutt $^{\circledR}$ ) with finasteride and placebo; the study showed no significant differences in in IPSS scores (P4.8 vs. P5.8 IPSS points), peak urine flow or residual urine volume between the extract combination in comparison to finasteride. As expected there were the usual adverse effects of finasteride such as, headaches, erectile dysfunction, delayed ejaculation and reduced volume, while the extract combination did not show significant adverse effects in comparison to placebo. The combination significantly improved BPH/LUTS symptoms in comparison to placebo improving IPSS scores by $17 \%$ [65].

Another placebo-controlled study lasting 3 months compared an Urtica extract with placebo in 41 men with BPH. Urtica was found to significantly improve IPSS scores; however, due to problems with palatability, this preparation was withdrawn from the market. Another placebo-controlled trial studied the effectiveness of Urtica extract capsules. The study found mild improvements in peak urine flow and total voided volume; but found no significant difference in IPSS scores [66].

The evidence obtained from these trials suggests that combination preparations of Urtica can provide some benefit for treatment of BPH/LUTS; however, monotherapy with Urtica does not appear to have significant benefits. More randomized trials need to be conducted before Urtica dioica can be considered as an effective option for the treatment of BPH/LUTS. Newer studies should take in account standardization of the different preparations and identification of the active components to elucidate mechanisms of action.

\section{CONCLUSION}

Extracts of saw palmetto (Serenoa repens) (alone or in combination with other phytotherapeutic products) have shown the strongest evidence for efficacy and tolerability. Though more studies remain to clarify all the contradictions showed in the different clinical studies.

Lycopersicum esculentum shows promise as a treatment for benign prostatic hyperplasia, however most of the available data on its effects are either experiments in cultured cells or preclinical information in animal models. The effects on oxidative stress and inflammation suggest that it might be useful. Randomized clinical trials are required to properly assess the efficacy of the extracts.

Pygeum africanum has few clinical trials and these lack the quality required to be considered as definitive, which severely hinders any attempt to recommend it for the treatment of BPH/LUTS. There is no convincing evidence to recommend Urtica dioica extracts alone in the treatment of $\mathrm{BPH}$; the available evidence suggests it can only be useful in combination with other extracts.

The widespread use of phytopharmaceutical agents in Europe is a testimony to the popularity of phytotherapy for the treatment of BPH symptoms. The economic benefits and the reduced potential for adverse effect in comparison to $\alpha$ blockers or finasteride is the most important factor for the popularity of its use. However, plant extracts have not yet demonstrated efficacy to significantly reduce BPH/LUTS or the need for more radical solutions such as surgery in severe cases compared with standard pharmacological treatment [67].

Despite all information being obtained from different clinical trials, there are still many questions to be addressed, many contradictory results from the clinical trials, show the need for more research, especially with more homogenous extract formulations and doses. The specific mechanisms of action as well as the active components of the extract have not yet been elucidated. Most importantly, very little research has been performed in obese individuals despite the evident link between obesity and prostate disease development.

\section{CONFLICT OF INTEREST}

The authors confirm that this article content has no conflicts of interest.

\section{ACKNOWLEDGEMENTS}

Declared none.

\section{REFERENCES}

[1] Galgani, J.; Ravussin, E. Energy metabolism, fuel selection and body weight regulation. Int. J. Obes. (Lond)., 2008, 32 (Suppl 7), S109-119.

[2] Carillon, J.; Romain, C.; Bardy, G.; Fouret, G.; Feillet-Coudray, C.; Gaillet, S.; Lacan, D.; Cristol, JP.; Rouanet, JM. Cafeteria diet induces obesity and insulin resistance associated with oxidative stress but not with inflammation: improvement by dietary supplementation with a melon superoxide dismutase. Free Radic. Biol. Med., 2013, 65, 254-261.

[3] Tewari, R.; Rajender, S.; Natu, S. M.; Dalela, D.; GOEL, A.; GOEL, M. M.; TANDON, P. Diet, obesity, and prostate health: are we missing the link? J. Androl., 2012, 33, 763-76.

[4] Blüher, M. Adipokines - removing road blocks to obesity and diabetes therapy. Mol. Metab., 2014, 3, 230-240.

[5] Wellman, P. J.; Clifford, P. S.; Rodriguez, J. A. Ghrelin and ghrelin receptor modulation of psychostimulant action. Front. Neurosci., 2013, 7, 171 .

[6] Michalakis, K.; Goulis, D. G.; Vazaiou, A.; Mintziori, G.; Polymeris, A.; Abrahamian-Michalakis A. Obesity in the ageing man. Metabolism., 2013, 62, 1341-1349.

[7] Mineur, Y. S.; Abizaid, A.; Rao, Y.; Salas, R.; DiLeone, R.; Gündisch, D.; Diano, S.; Biasi, M.; Horvath, T.; Gao, X.; Picciotto, M. Nicotine decreases food intake through activation of POMC neurons. Science, 2011, 332, 1330-1332.

[8] Galgani, J. E.; Ravussin, E. Postprandial whole-body glycolysis is similar in insulin-resistant and insulin-sensitive non-diabetic humans. Diabetologia, 2012, 55, 737-742.

[9] Piya, M. K.; McTernan, P. G.; Kumar, S. Adipokine inflammation and insulin resistance: the role of glucose, lipids and endotoxin. $J$. Endocrinol., 2013, 216, T1-T15.

[10] Physical Status: The use and interpretation of anthropometry, 2008

[11] Alcaraz, A.; Hammerer, P.; Tubaro, A.; Schröder, F. H.; Castro R Is there evidence of a relationship between benign prostatic hyperplasia and prostate cancer? Findings of a literature review. Eur. Urol., 2009, 55, 864-873.

[12] Hizli, F.; Uygur, M. C. A prospective study of the efficacy of Serenoa repens, tamsulosin, and Serenoa repens plus tamsulosin treatment for patients with benign prostate hyperplasia. Int. Urol. Nephrol., 2007, 39, 879-886.

[13] Carraro, J. C.; Raynaud, J. P.; Koch, G.; Chisholm, G. D.; Di Silverio, F.; Teillac, P.; Da Silva, FC.; Cauquil, J.; Chopin, DK.; Hamdy, FC.; Hanus, M.; Hauri, D.; Kalinteris, A.; Marencak, J.; Perier, A.; Perrin, P. Comparison of phytotherapy (Permixon) with finasteride in the treatment of benign prostate hyperplasia: a randomized international study of 1,098 patients. Prostate, 1996, 29, 231-240; discussion 241-242. 
[14] Vikram, A.; Kushwaha, S.; Jena, G. B. Relative influence of testosterone and insulin in the regulation of prostatic cell proliferation and growth. Steroids, 2011, 76, 416-423.

[15] Ford, N. A.; Moran, N. E.; Smith, J. W.; Clinton, S. K.; Erdman, JW. An interaction between carotene-15,15'-monooxygenase expression and consumption of a tomato or lycopene-containing diet impacts serum and testicular testosterone. Int. J. Cancer, 2012, 131, E143-148.

[16] Golomb, E.; Kruglikova, A.; Dvir, D.; Parnes, N.; Abramovici A. Induction of atypical prostatic hyperplasia in rats by sympathomimetic stimulation. Prostate, 1998, 34, 214-221.

[17] Ribeiro, D. L.; Pinto, M. E.; Maeda, S.Y.; Taboga, S.R.; Góes RM. High fat-induced obesity associated with insulin-resistance increases FGF-2 content and causes stromal hyperplasia in rat ventral prostate. Cell Tissue Res., 2012, 349, 577-88.

[18] Salvador, J. A. R.; Pinto, R. M. A.; Silvestre, S. M. Steroidal 5 $\alpha-$ reductase and 17 $\alpha$-hydroxylase/17,20-lyase (CYP17) inhibitors useful in the treatment of prostatic diseases. J. Steroid Biochem. Mol. Biol., 2013, 137, 199-222.

[19] Kang, D. Il; Chung, J. Il. Current status of $5 \alpha$-reductase inhibitors in prostate disease management. Korean J. Urol., 2013, 54, 213219.

[20] Timms, B. G.; Hofkamp, L. E. Prostate development and growth in benign prostatic hyperplasia. Differentiation., 2011, 82, 173-183.

[21] Wang, Z.; Olumi, A. F. Diabetes, growth hormone-insulin-like growth factor pathways and association to benign prostatic hyperplasia. Differentiation. 2011, 82, 261-271.

[22] Van Coppenolle, F.; Le Bourhis, X.; Carpentier, F.; Delaby, G.; Cousse, H.; Raynaud, J. P.; Dupouy, J. P.; Prevarskaya, N. Pharmacological effects of the lipidosterolic extract of Serenoa repens (Permixon) on rat prostate hyperplasia induced by hyperprolactinemia: comparison with finasteride. Prostate, 2000, 43, 49-58.

[23] Irigaray, P.; Newby, J. A.; Lacomme, S.; Belpomme, D. Overweight/obesity and cancer genesis: more than a biological link. Biomed. Pharmacother., 2007, 61, 665-78.

[24] Ozten-Kandaş, N.; Bosland, M. C. Chemoprevention of prostate cancer: Natural compounds, antiandrogens, and antioxidants - In vivo evidence. J. Carcinog., 2011, 10, 27.

[25] Golomb, E.; Rosenzweig, N.; Eilam, R.; Abramovici, A. Spontaneous hyperplasia of the ventral lobe of the prostate in aging genetically hypertensive rats. J. Androl., 2000, 21, 58-64.

[26] Scavuzzo, A.; Favilla, V.; Cimino, S.; Madonia, M.; Li Volti, G.; Morgia, G. The relationship between oxidative stress and obesity in prostate disease. Urologia, 2012, 79, 156-158.

[27] Baltaci, S.; Orhan, D.; Gögüs, C.; Türkölmez, K.; Tulunay, O.; Gögüs, O. Inducible nitric oxide synthase expression in benign prostatic hyperplasia, low- and high-grade prostatic intraepithelial neoplasia and prostatic carcinoma. BJU Int., 2001, 88, 100-103.

[28] Ückert, S.; Waldkirch, E. S.; Merseburger, A. S.; Kuczyk, M. A; Oelke, M.; Hedlund, P. Phosphodiesterase type 5 (PDE5) is colocalized with key proteins of the nitric oxide/cyclic GMP signaling in the human prostate. World J. Urol., 2013, 31, 609-614.

[29] Dey, A.; Lang, R. J.; Exintaris, B. Nitric oxide signaling pathways involved in the inhibition of spontaneous activity in the guinea pig prostate. J. Urol., 2012, 187, 2254-2260.

[30] Lee, S.; Min, H. G.; Choi, S. H.; Kim, Y. J.; Oh, S. W.; Kim, Y. J.; Park, Y.; Kim, S. S. Central obesity as a risk factor for prostatic hyperplasia. Obesity (Silver Spring)., 2006, 14, 172-179.

[31] Moul, S.; McVary, K. T. Lower urinary tract symptoms, obesity and the metabolic syndrome. Curr. Opin. Urol., 2010, 20, 7-12.

[32] Spatafora, S.; Casarico, A.; Fandella, A.; Galetti, C.; Hurle, R.; Mazzini, E.; Niro, C.; Perachino, M.; Sanseverino, R.; Pappagallo, GL. Evidence-based guidelines for the treatment of lower urinary tract symptoms related to uncomplicated benign prostatic hyperplasia in Italy: updated summary from AURO.it. Ther. Adv. Urol., 2012, 4, 279-301.

[33] Altavilla, D.; Bitto, A.; Polito, F.; Irrera, N. The combination of serenoa repens, relenium and lycopene is more effective than serenoa repens alone to prevent hormone dependent prostatic growth. J. ..., 2011, 186, 1524-1529.

[34] Lowe, F.C. Phytotherapy in the management of benign prostatic hyperplasia. Urology, 2001, 58, 71-76; discussion 76-77.

[35] Dreikorn, K. The role of phytotherapy in treating lower urinary tract symptoms and benign prostatic hyperplasia. World J. Urol., 2002, 19, 426-435.
[36] Gerber, G.S. Phytotherapy for benign prostatic hyperplasia. Curr. Urol. Rep., 2002, 3, 285-291.

[37] Booker, A.; Suter, A.; Krnjic, A.; Strassel, B.; Zloh, M.; Said, M.; Heinrich, M. A phytochemical comparison of saw palmetto products using gas chromatography and (1) H nuclear magnetic resonance spectroscopy metabolomic profiling. J. Pharm. Pharmacol., 2014, 66, 811-822.

[38] Wilt, T. J.; Ishani, a; Rutks, I.; MacDonald, R. Phytotherapy for benign prostatic hyperplasia. Public Health Nutr., 2000, 3, 459472 .

[39] Gerber, G.S.; Zagaja, G.P.; Bales, G.T.; Chodak, G.W.; Contreras, B. A. Saw palmetto (Serenoa repens) in men with lower urinary tract symptoms: effects on urodynamic parameters and voiding Symptoms. urology, 1998, 51, 1003-1007.

[40] Al-Shukri, S. H.; Deschaseaux, P.; Kuzmin, I. V; Amdiy, R. R., Early urodynamic effects of the lipido-sterolic extract of Serenoa repens (Permixon(R)) in patients with lower urinary tract symptoms due to benign prostatic hyperplasia. Prostate Cancer Prostatic Dis., 2000, 3, 195-199.

[41] Boyle, P.; Robertson, C.; Lowe, F.; Roehrborn, C. Updated metaanalysis of clinical trials of Serenoa repens extract in the treatment of symptomatic benign prostatic hyperplasia. BJU Int., 2004, 93, 751-6.

[42] Lee, J.; Andriole, G.; Avins, A.; Crawford, E. D.; Foster, H.; Kaplan, S.; Kreder, K.; Kusek, J.; McCullough, A.; McVary, K.; Meleth, S.; Naslund, M.; Nickel, J. C.; Nyberg, L.; Roehrborn, C.; Dale Williams, O.; Barry, M.; Redesigning a large-scale clinical trial in response to negative external trial results: the CAMUS study of phytotherapy for benign prostatic hyperplasia. Clin. Trials, 2009, 6, 628-36.

[43] Morgia, G.; Mucciardi, G.; Galì, A; Madonia, M.; Marchese, F.; Di Benedetto, A.; Romano, G.; Bonvissuto, G.; Castelli, T.; Macchione, L.; Magno, C. Treatment of chronic prostatitis/chronic pelvic pain syndrome category IIIA with Serenoa repens plus selenium and lycopene (Profluss) versus S. repens alone: an Italian randomized multicenter-controlled study. Urol. Int., 2010, 84, 400406.

[44] Morgia, G.; Cimino, S.; Favilla, V.; Russo, G. I.; Squadrito, F.; Mucciardi, G.; Masieri, L.; Minutoli, L.; Grosso, G.; Castelli, T. Effects of Serenoa repens, selenium and lycopene (Profluss ${ }^{\circledR}$ ) on chronic inflammation associated with benign prostatic hyperplasia: results of "FLOG" (Flogosis and Profluss in Prostatic and Genital Disease), a multicentre Italian study. Int. Braz J Urol, 2013, 39, 214-221.

[45] Kim, J. Y.; Paik, J. K.; Kim, O.Y.; Park, H. W.; Lee, J. H.; Jang, Y.; Lee, J. H. Effects of lycopene supplementation on oxidative stress and markers of endothelial function in healthy men. Atherosclerosis, 2011, 215, 189-195.

[46] Erdman, J.W.; Ford, N. A.; Lindshield, B. L. Are the health attributes of lycopene related to its antioxidant function? Arch. Biochem. Biophys., 2009, 483, 229-235.

[47] Palozza, P.; Catalano, A.; Simone, R.; Cittadini, A. Lycopene as a guardian of redox signalling. Acta Biochim. Pol., 2012, 59, 21-25.

[48] Heber, D.; Lu, Q. Y. Overview of mechanisms of action of lycopene. Exp. Biol. Med. (Maywood)., 2002, 227, 920-923.

[49] Rafi, M. M.; Kanakasabai, S.; Reyes, M. D.; Bright, J. J. Lycopene modulates growth and survival associated genes in prostate cancer. J. Nutr. Biochem., 2013, 24, 1724-1734.

[50] Yang, C. M.; Lu, I. H.; Chen, H. Y.; Hu, M. L. Lycopene inhibits the proliferation of androgen-dependent human prostate tumor cells through activation of PPAR $\gamma-\mathrm{LXR} \alpha-\mathrm{ABCA} 1$ pathway. J. Nutr. Biochem., 2012, 23, 8-17.

[51] Liu, A. G.; Volker, S. E.; Jeffery, E. H.; Erdman, J. W. Feeding tomato and broccoli powders enriched with bioactives improves bioactivity markers in rats. J. Agric. Food Chem., 2009, 57, 73047310.

[52] Polívková, Z.; Šmerák, P.; Demová, H.; Houška, M. Antimutagenic effects of lycopene and tomato purée. J. Med. Food, 2010, 13, 1443-1450.

[53] Matulka, R. A.; Hood, A. M.; Griffiths, J. C. Safety evaluation of a natural tomato oleoresin extract derived from food-processing tomatoes. Regul. Toxicol. Pharmacol., 2004, 39, 390-402.

[54] Porrini, M.; Riso, P. Lymphocyte lycopene concentration and DNA protection from oxidative damage is increased in women after a short period of tomato consumption. J. Nutr., 2000, 130, 189-192. 
[55] Colado-Velazquez, J. I.; Bravo, G.; Mailloux-Salinas, P.; EspinosaJuárez, J. V. Extracto de Tomate (Lycopersicum esculentum) para el tratamiento de hiperplasia de próstata en obesidad, MX/a/2014/015563, 2014.

[56] Chen, L.; Stacewicz-Sapuntzakis, M.; Duncan, C. ;Sharifi, R.; Ghosh, L.; Van Breemen, R.; Ashton, D.; Bowe, P. Oxidative DNA damage in prostate cancer patients consuming tomato sauce-Based entrees as a whole-food intervention. JNCI J. Natl. Cancer Inst., 2001, 93, 1872-1879.

[57] Edinger, M. S.; Koff, W. J. Effect of the consumption of tomato paste on plasma prostate-specific antigen levels in patients with benign prostate hyperplasia. Braz. J. Med. Biol. Res., 2006, 39, 1115-1119.

[58] Schwarz, S.; Obermüller-Jevic, U .C.; Hellmis, E.; Koch, W.; Jacobi, G.; Biesalski, H. K. Lycopene inhibits disease progression in patients with benign prostate hyperplasia. J. Nutr., 2008, 138, 49-53.

[59] La Placa, M.; Pazzaglia, M.; Tosti, A. Lycopenaemia. J. Eur. Acad. Dermatology Venereol., 2000, 14, 311-312.

[60] Levin, R. M.; Das, A K. A scientific basis for the therapeutic effects of Pygeum africanum and Serenoa repens. Urol. Res., 2000, 28, 201-9.

[61] Levin, R. M.; Whitbeck, C.; Horan, P.; Bellamy, F. Low-dose tadenan protects the rabbit bladder from bilateral ischemia/ reperfusion-induced contractile dysfunction. Phytomedicine, 2005, $12,17-24$.

[62] Edgar, A. D.; Levin, R.; Constantinou, C. E.; Denis, L. A critical review of the pharmacology of the plant extract of Pygeum africanum in the treatment of LUTS. Neurourol. Urodyn., 2007, 26, 458-63; discussion 464.

[63] Schleich, S.; Papaioannou, M.; Baniahmad, A.; Matusch, R. Extracts from Pygeum africanum and other ethnobotanical species with antiandrogenic activity. Planta Med., 2006, 72, 807-13.

[64] Krzeski, T.; Kazón, M.; Borkowski, A.; Witeska, A.; Kuczera. J. Combined extracts of Urtica dioica and Pygeum africanum in the treatment of benign prostatic hyperplasia: double-blind comparison of two doses. Clin. Ther., 1993, 15, 1011-1020.

[65] Sökeland, J. Combined sabal and urtica extract compared with finasteride in men with benign prostatic hyperplasia: analysis of prostate volume and therapeutic outcome. BJU Int., 2000, 86, 439442.

[66] Vontobel, H. P.; Herzog, R.; Rutishauser, G.; Kres, H. Results of a double-blind study on the effectiveness of ERU (extractum radicis Urticae) capsules in conservative treatment of benign prostatic hyperplasia. Urologe. A, 1985, 24, 49-51.

[67] McConnell, J. D.; Roehrborn, C. G.;Bautista, O. M.; Andriole, G. L.; Dixon, C. M.; Kusek, J. W.; Lepor, H.; McVary, K. T.; Nyberg, L. M. J.; Clarke, H. S.; Crawford, E. D.; Diokno, A.; Foley, J. P.; Foster, H. E.; Jacobs, S. C.; Kaplan, S. A.; Kreder, K. J.; Lieber, M. M.; Lucia, M. S.; Miller, G. J.; Menon, M.; Milam, D. F.; Ramsdell, J. W.; Schenkman, N. S.; Slawin, K. M.; Smith, J. A. The long-term effect of doxazosin, finasteride, and combination therapy on the clinical progression of benign prostatic hyperplasia. N. Engl. J. Med., 2003, 349, 2387-2398.

(C) Colado Velazquez et al.; Licensee Bentham Open.

This is an open access article licensed under the terms of the Creative Commons Attribution Non-Commercial License (http://creativecommons.org/licenses/bync/3.0/), which permits unrestricted, non-commercial use, distribution and reproduction in any medium, provided the work is properly cited. 